\title{
TRIBUTAÇÃO AMBIENTAL: UMA ANÁLISE SOBRE O IPTU VERDE NO MUNICÍPIO DE SALVADOR-BA
}

\author{
Maíra Correia Cavalcanti Dantas \\ Universidade Federal da Bahia (UFBA), Bahia \\ mairaccdantas@gmail.com \\ Tagore Trajano de Almeida Silva \\ Universidade Federal da Bahia (UFBA), Bahia \\ tagoretrajano@gmail.com
}

\begin{abstract}
RESUMO: O Programa de Certificação Sustentável IPTU Verde implementado no município de Salvador - BA pelo Decreto $\mathrm{n}^{\circ} 29.100 / 2017$ concede descontos no imposto aos empreendimentos imobiliários que adotarem as medidas de sustentabilidade previstas. $\mathrm{O}$ trabalho busca responder ao seguinte problema: o incentivo fiscal ambiental IPTU Verde de Salvador -BA é um estímulo eficaz ao surgimento de empreendimentos sustentáveis na cidade? Para tanto, foi desenvolvida uma pesquisa do tipo bibliográfica, abordagem do tema a partir de referenciais teóricos, aliada à aplicação da metodologia descritiva com a realização de questionários locais. Serão abordadas as questões relativas à dimensão extrafiscal da tributação ambiental e os incentivos fiscais ambientais, seus fundamentos e atuação como indutores de condutas positivas nos contribuintes, apresentando também os limites constitucionais à sua concessão. Por fim, o trabalho concluiu que o benefício fiscal IPTU Verde tem sua abrangência restrita a alguns poucos empreendimentos já certificados no município, portanto, ainda não pode ser considerado uma solução urbana eficaz voltada à sustentabilidade e à proteção ambiental.
\end{abstract}

PALAVRAS-CHAVE: IPTU Verde. Extrafiscalidade. Incentivos fiscais ambientais. Sustentabilidade.

\section{Environmental taxes: An analysis of the green municipal property tax in Salvador-BA}

ABSTRACT: The Sustainable Certification Program implemented in the city of Salvador - BA by Decree No. 29.100/2017 grants tax rebates to real estate projects that adopt sustainability measures. The work intend to answer the following question: Is the environmental tax break, known as the green municipal property tax, implemented in Salvador -BA an effective way to encourage sustainable constructions in the city? Therefore, a bibliographic research was developed, approaching the theme from theoretical references, allied to the application of local questionnaires. It will also be adressed issues related to the non-fiscal purposes taxation of the environmental taxes, environmental tax breaks, their constitucional bases as well as their role to encourage positive behavior in taxpayers. Finally, the study concludes that the green property tax benefit and its Program are limited to a few certified buildings in the city, so it cannot yet be considered an effective urban solution to achieve sustainable and environmental goals.

KEYWORDS: Green municipal property tax. Non-fiscal purpose taxation. Environmental tax breaks. Sustainability. 


\section{INTRODUÇÃo}

Pesquisas apontam que no Brasil a construção civil é uma das atividades humanas que causam mais impactos negativos ao meio ambiente. Foi com o objetivo de alterar esta realidade que alguns municípios do País instituíram o incentivo fiscal ambiental IPTU Verde. A partir da concessão de isenções e descontos no valor a ser pago pelo imposto sobre a propriedade urbana, o poder local busca incentivar os empreendimentos a desenvolverem ações voltadas à preservação ambiental e à utilização de tecnologias verdes nas edificações.

O Programa de Certificação Sustentável IPTU Verde desenvolvido no município de Salvador-BA é inédito no País, tendo obtido reconhecimento internacional na Conferência das Nações Unidas sobre Mudanças Climáticas de 2015 (COP 21). O incentivo fiscal IPTU Verde foi implementado no Município no ano de 2015 e, atualmente, é regulamentado pelo Decreto $\mathrm{Mu}$ nicipal $n^{\circ} 29.100 / 2017$.

O presente artigo pretende responder ao seguinte problema: O incentivo fiscal ambiental IPTU Verde de Salvador -BA é um estímulo eficaz ao surgimento de empreendimentos sustentáveis na cidade? Para tanto, foi desenvolvida uma pesquisa do tipo bibliográfica, com a análise do tema a partir de referenciais teóricos pré-existentes, ademais, foi utilizada a metodologia descritiva, com a aplicação de questionários direcionados aos órgãos municipais responsáveis pela implementação do IPTU Verde e aos empreendimentos contemplados pelo benefício. Também serão abordadas as questões relativas à extrafiscalidade da tributação com viés ambiental e aos incentivos fiscais ambientais.

No primeiro momento, será apresentada a dimensão extrafiscal dos tributos, com ênfase nos incentivos fiscais e as vantagens de sua utilização como instrumento de proteção ambiental. Em complemento, serão analisadas as limitações constitucionais ao poder do ente público para conceder incentivos fiscais na área ambiental. Após, segue-se à análise do incentivo fiscal IPTU Verde e sua implementação em alguns municípios do País.

A última parte do trabalho trata sobre o Programa de Certificação Sustentável IPTU Verde de Salvador-BA, o contexto em que foi criado, a legislação municipal aplicável e os critérios subjetivos e objetivos para participação no Programa. Por fim, foram apresentados os resultados da implementação do benefício fiscal no município e uma análise crítica acerca da sua eficácia e das limitações constitucionais ao poder do ente municipal para concedê-lo.

\section{EXTRAFISCALIDADE E A PROTEÇÃO AMBIENTAL NO BRASIL}

A doutrina tradicional esclarece que, do ponto de vista da ciência das finanças, é possível classificar o tributo de diversas formas, dentre as quais Hugo de Brito Machado ${ }^{1}$ evidencia a classificação quanto aos efeitos dos tributos em fiscais, extrafiscais e parafiscais. Os tributos fiscais são aqueles cujo fim principal é arrecadar fundos para o Estado. Por outro lado, a tributação extrafiscal tem como objetivo a intervenção do Estado na economia e em outras áreas de interesse através da indução de comportamentos nos contribuintes, deixando a arrecadação em segundo plano. Os tributos parafiscais têm como objetivo o custeio de atividades que não integram funções próprias do Estado, mas que são por ele desenvolvidas através de entidades específicas, a exemplo das contribuições profissionais.

1 MACHADO, H. de B. Curso de Direito Tributário. 38. ed. ver. e atual. São Paulo, SP: Malheiros, 2017. p. 68 
Segundo Geraldo Ataliba ${ }^{2}$, a extrafiscalidade tem como fundamento o uso de instrumentos tributários para a consecução de fins diversos da mera arrecadação, como estimulantes, indutores e coibidores de comportamento, de forma a realizar outros valores constitucionalmente consagrados. Hugo de Brito Machado ${ }^{3}$ evidencia que o uso da tributação em seu aspecto extrafiscal é um produto do estado intervencionista moderno, tanto é que a Constituição Federal de 1988 (CFRB/88) instituiu no Brasil a estrutura de um Estado Social que exige a intervenção do Estado na economia para atender aos interesses sociais, econômicos e ambientais.

A tutela constitucional do meio ambiente foi introduzida pela Constituição Federal de 1988, que em seu art. 225, caput, reconhece o Direito Fundamental ao Meio Ambiente Ecologicamente Equilibrado e reitera que todos têm o dever de defendê-lo e preservá-lo para as presentes e futuras gerações. O texto constitucional estabelece, também, como um dos princípios da ordem econômica, art. 170, VI, a defesa do meio ambiente e autoriza a concessão de tratamento diferenciado aos produtos, serviços e aos seus processos de elaboração, segundo o nível de impacto ambiental.

Assim, os tributos ambientais servem como instrumento para promoção da tutela constitucional do meio ambiente. Santos, Sellman e Vasques ${ }^{4}$ ressaltam a importância da atuação do Estado que tributa em defesa do meio ambiente e reconhecem que, neste campo específico, utiliza-se a tributação em seu viés extrafiscal com o objetivo de estimular práticas sustentáveis e desestimular condutas que gerem danos ao meio ambiente.

A tributação ambiental também encontra respaldo no Princípio do Poluidor-Pagador, princípio de direito internacional ambiental previsto no art. $4^{\circ}$, VII, da Lei $n^{\circ}$ 6.938/1981, e eleito como um dos Princípios da Declaração do Rio sobre Meio Ambiente e Desenvolvimento ${ }^{5}$. Luís Eduardo Schoueri ${ }^{6}$ resume o princípio do poluidor-pagador como a ideia de que aquele que causa danos ao meio ambiente deve suportar os custos econômicos da sua recuperação e as perdas sofridas pela coletividade.

Por sua vez, Consuelo Yatsuda Moromizato Yoshida ${ }^{7}$ reconhece que o princípio do poluidor-pagador possui uma concepção mais alargada e abrange também a prevenção do dano ambiental. Considerando o duplo caráter do instituto, repressivo e preventivo, os instrumentos tributários poderão ser utilizados tanto de modo a onerar os agentes poluidores, com a instituição e a graduação dos tributos que incidem sobre a atividade, como promovendo a desoneração dos sujeitos passivos que não se enquadrem como poluidores, através da concessão de incentivos e benefícios fiscais ${ }^{8}$.

Portanto, é no campo da extrafiscalidade que o legislador tributário encontra espaço para estimular e desestimular condutas em prol da proteção do meio ambiente através da imposição de uma carga tributária progressiva ou regressiva sobre o contribuinte.

2 ATALIBA, G. Hipótese de incidência tributária. 5. ed. São Paulo: Malheiros, 1999. p. 233

MACHADO, H. de B. Op. cit. p. 69.

4 VASQUES, D. F., SANTOS, L. C. F., SELLMAN, M. Z. Op. cit., p. 39

5 ORGANIZAÇÃO DAS NAÇÕES UNIDAS. Declaração do Rio sobre meio ambiente e desenvolvimento, Rio de Janeiro, RJ, 1992. Disponível em: http://www.meioambiente.pr.gov.br/arquivos/File/agenda21/Declaracao Rio Meio_Ambiente Desenvolvimento.pdf Acesso em: 15 out. 2019.

6 SCHOUERI, L. E. Normas tributárias indutoras em matéria ambiental. In: TÔRRES, H. T. (org). Direito tributário ambiental. São Paulo, SP: Malheiros, 2005. p. 236 - 237

7 YOSHIDA, C. Y. M. Ênfase na prevenção. A utilização econômica dos bens ambientais e suas implicações. In: TÔRRES, H. T. (org). Direito tributário ambiental. São Paulo, SP: Malheiros, 2005. p. 544

8 PINTO, K. A. V. S. Op cit. p. 128 


\section{OS INCENTIVOS FISCAIS COMO ESTÍMULO À PRESERVAÇÃO DO MEIO AMBIENTE}

O Estado poderá atuar em defesa do meio ambiente de modo a estimular atividades não agressoras através da premiação dos agentes econômicos ou, de maneira coativa, impondo aos agentes poluidores sanções administrativas e criminais, obrigações de fazer e não fazer, bem como tributando suas atividades com o objetivo de atender aos interesses ambientais ${ }^{9}$.

Regina Helena $\operatorname{Costa}^{10}$ reconhece que, em matéria ambiental, o Brasil tradicionalmente adota o sistema de "comando e controle", em que incumbe ao legislador editar normas dirigidas aos particulares, instando-os a adotar comportamentos positivos em prol do meio ambiente, ao tempo em que a Administração fiscaliza seu cumprimento ao exercer o poder de polícia administrativa. No entanto, conforme mencionado pela autora, a manutenção da infraestrutura do sistema tradicional e a sua fiscalização, implicam em custos elevados para o Estado, que poderiam ser reduzidos através da adoção concomitante de um sistema de tributação ambiental.

Os tributos estão dentre os instrumentos econômicos da política ambiental internacional estabelecidos pela Organização para Cooperação e Desenvolvimento Econômico (OCDE) no relatório "Working Party on Economic and environmental Policy Integration” de 1999. Isto demonstra que a política ambiental faz uso tanto de instrumentos econômicos quanto de mecanismos de regulação direta, como proibições e sanções, para a consecução dos seus objetivos ${ }^{11}$.

Para Keziah Alessandra Viana da Silva Pinto ${ }^{12}$, o incentivo fiscal é um dos mais importantes instrumentos fiscais de intervenção na economia utilizados pelo Estado, especialmente no campo ambiental, pois atuam como um estímulo direto ao contribuinte para a adoção de comportamentos ambientalmente positivos. A autora reconhece, também, que a instituição de incentivos e benefícios fiscais com finalidade ambiental tem respaldo no texto constitucional.

A Constituição Federal em seu art. 170, VI, autoriza o tratamento tributário diferenciado conforme o impacto ambiental dos produtos e serviços, de seus processos de elaboração e prestação. Em adendo, a Lei Federal n ${ }^{\circ}$ 6.938/81, que estabelece a Política Nacional do Meio Ambiente, prevê como um dos seus instrumentos, art. $9^{\circ}$, inciso $\mathrm{V}$, os "incentivos à produção e instalação de equipamentos e a criação ou absorção de tecnologia, voltados para a melhoria da qualidade ambiental"13.

Segundo Geraldo Ataliba e J.A. Lima Gonçalves ${ }^{14}$, os incentivos fiscais atuam como uma espécie de "alívio" da carga tributária concedido por lei aos contribuintes, com o propósito de estimular a adoção de boas condutas, ao tempo em que desestimulam condutas negativas para o desenvolvimento do País. São considerados incentivos fiscais as isenções, remissões, anistia, moratória, redução de alíquotas e deduções na base de cálculo, manutenção de créditos, e, até mesmo, a redução do tributo devido, pagando-se apenas parte dele.

9 Ibid, loc. cit.

${ }^{10}$ COSTA, R. H. Op. cit., p. 322

${ }^{11}$ MOLINA, P. M. H., VASCO, D. C. Marco conceptual, constitucional y comunitario de la fiscalidad ecológica. In: TÔRRES, H. T. (org). Direito tributário ambiental. São Paulo, SP: Malheiros, 2005. p. 158 - 16

12 PINTO, K. A. V. S. Op cit. p. 340 e 341

13 YOSHIDA, C. Y. M. Op. cit. p. 534 - 535

${ }^{14}$ ATAliBA, G., GONÇALVES, J. A. L. Crédito-prêmio de IPI - Direito adquirido - Recebimento em dinheiro. Revista de Direito Tributário. São Paulo, SP: Revista dos Tribunais, v. 15, n. 55, p. 162 - 179, jan/mar.1991. p. 166 167 
Heleno Taveira Tôrres ${ }^{15}$ diz que na área ambiental, para além da pretensão de criar impostos, é importante que o Estado adote medidas que vinculem os direitos às subvenções ou isenções ao cumprimento da legislação ambiental. O dever de proteção do meio ambiente poderia servir, portanto, como determinante negativo do exercício da competência, sendo motivo para justificar a política fiscal de desoneração da carga tributária em prol de certas categorias.

Alejandro C. Altamirano ${ }^{16}$ ao tratar sobre as vantagens da criação de incentivos fiscais com finalidade ambiental, qualifica-os como um instrumento efetivo de controle da poluição, uma vez que é o contribuinte quem vai avaliar a conveniência de se adequar à norma que concede o incentivo, segundo seus objetivos comerciais. Para o autor, uma política tributária que utiliza instrumentos econômicos em prol da preservação do meio ambiente deve privilegiar os estímulos tributários e incentivos econômicos, ao invés de aplicar taxas e impostos, visto que o seu uso estimula a otimização do impacto ambiental, além do que são medidas menos onerosas para o Estado, quando comparados aos gastos para corrigir a degradação posterior ${ }^{17}$.

O Estado poderá fazer uso dos incentivos fiscais para estimular a produção e a comercialização de produtos sustentáveis, em contraponto à atuação coercitiva. Para Heron José de Santana Gordilho ${ }^{18}$, uma das principais vantagens dos incentivos fiscais está em seu caráter preventivo, que, ao contrário da política repressiva, vão atuar antes da ocorrência do dano ambiental. O autor entende também que o caráter não-coativo destes instrumentos propicia a produção e a comercialização de produtos sustentáveis pelos agentes econômicos.

Os incentivos fiscais, como um instrumento tributário de caráter extrafiscal, apresentamse como um dos meios utilizados pelo Estado para induzir os particulares a adotarem condutas ambientalmente direcionadas, em complemento à instituição e majoração dos tributos.

\subsection{Os limites constitucionais ao poder de tributar aplicados aos incentivos}

\section{fiscais ambientais}

Ao tratar dos incentivos e benefícios fiscais ambientais, é de suma importância ater-se à questão dos limites à sua concessão, sob pena de o instituto converter-se em um verdadeiro favor fiscal prestado a alguns poucos agentes econômicos, sem uma contrapartida ambiental relevante. Para José Souto Maior Borges ${ }^{19}$, a antinomia das isenções com um regime de favorecimento fiscal está no fato de que o regime legal-ordinário da tributação deverá ser compatível com os preceitos constitucionais.

Aliomar Baleeiro ${ }^{20}$ refere-se ao tema sob o título das "Limitações Constitucionais ao Poder de Tributar". Os princípios limitadores do poder de tributar submetem o legislador ordinário à critérios formais e materiais de observância obrigatória e, de forma inversa, também vinculam o legislador na concessão de isenções; o que José Souto Maior Borges denomina "Limitações Constitucionais ao Poder de Isentar" ${ }^{\prime \prime}$.

\footnotetext{
15 TÔRRES, H. T. Op. cit. p. 110

${ }^{16}$ ALTAMIRANO, A. C. El derecho tributario ante la constitucionalización del derecho a un medio ambiente sano. In: TÔRRES, H. T. (org). Direito tributário ambiental. São Paulo, SP: Malheiros, 2005. p. 445 - 526. p. 324

${ }^{17}$ Ibid, p. 80

${ }^{18}$ SANTANA, H. J. de. Justiça fiscal e extrafiscal nos tributos ambientais. Revista do Programa de Pós-Graduação em Direito da UFBA/ Faculdade de Direito, Salvador: EDUFBA, n. 11, p. 37 - 56, jan./dez. 2004. p. 39

${ }^{19}$ BORGES, J. S. M. Isenções tributárias. 2. ed. São Paulo, SP: Sugestões literárias S/A, 1980. p. 59

${ }^{20}$ BALEEIRO, A. Op. cit. p. 12

${ }^{21}$ BORGES, J. S. M. Op. cit. p. 21 - 37
} 
A Constituição Federal ao estabelecer um regime severo de limitações ao poder de tributar, reveste o instituto da segurança jurídica necessária para torná-lo mais atrativo aos particulares. Geraldo Ataliba e J.A Lima Gonçalves ${ }^{22}$ observam que as pessoas e as empresas respondem afirmativamente aos apelos governamentais formulados a partir dos incentivos fiscais, desde que tenham a garantia de que tais incentivos, estabelecidos por lei, serão por ela mantidos, e devem estar seguros de que serão respeitados pela administração, sob pena de a lei incentivadora ter sua eficácia comprometida.

Renata Figueirêdo Brandão ${ }^{23}$ aponta que, para além dos limites impostos pela Constituição ao poder de tributar, como as regras de competência, a legalidade e a igualdade, também deverão ser levados em conta os efeitos decorrentes da concessão destes incentivos, como a renúncia de receita pelo Estado. Com o advento da Lei Complementar no 101/2000, Lei de Responsabilidade Fiscal, passa a ser obrigatório que a União, Estados, Municípios e o Distrito Federal, demonstrem que o montante renunciado em razão da concessão de incentivos e benefícios fiscais foi considerado na estimativa de receita da Lei Orçamentária e que não comprometerá as metas de resultados fiscais da Lei de Diretrizes Orçamentárias.

\subsubsection{Competência}

A competência tributária é o poder de instituir e cobrar tributos atribuído pela Constituição Federal à União, Estados, Municípios e Distrito Federal. A competência tributária representa, simultaneamente, uma autorização e uma limitação constitucional ao exercício do poder de tributar. Ao deixar de tributar determinados contribuintes ou tributando-os apenas em parte, o ente público se abstém do exercício da competência tributária, daí a ideia de que o poder de isentar corresponde ao poder de tributar ao inverso ${ }^{24}$.

Assim, para que sejam concedidos incentivos fiscais aos particulares, o Ente Público deverá seguir as mesmas regras de competência impostas pela Constituição para a instituição dos tributos. Em relação aos incentivos fiscais aplicados à área ambiental, deverá ser observado se o Ente Público detém competência legislativa tributária para conceder o benefício no âmbito do tributo escolhido e se possui competência material para tratar sobre a questão de fato sobre a qual incide a desoneração.

Luís Eduardo Schoueri ${ }^{25}$ ressalta que, do ponto de vista da fiscalidade, a competência tributária é estabelecida pelos art. 153 a 156 da Constituição, porém, quando se reconhece na norma uma função indutora, extrafiscalidade, deverá ser investigado se a intervenção sobre o Domínio Econômico não extrapola a competência material do ente tributante.

Em relação à competência material, a Constituição em seu art. 23, incisos VI e VII, estabelece a competência comum de todos os entes públicos para proteção do meio ambiente, combate à poluição, preservação de florestas etc. Ademais, o texto constitucional determina que compete à União, Estados, Municípios e Distrito Federal legislar concorrentemente sobre "florestas, caça, pesca, fauna, conservação da natureza, defesa do solo e dos recursos naturais, proteção do meio ambiente e controle da poluição", art. 24, IV, CFRB/88.

\footnotetext{
22 ATALIBA, G., GONÇALVES, J. A. L. Op. cit. p. 169

${ }^{23}$ BRANDÃO, R. F. Op. cit. p. $136-171$

${ }^{24}$ BORGES, J. S. M. Op. cit. p. $19-21$

${ }^{25}$ SCHOUERI, L. E. Op. cit. p. 251 - 252
} 
Portanto, a análise da constitucionalidade dos incentivos e benefícios fiscais com finalidade ambiental perpassa pela questão da competência do Ente Público para promover a desoneração, devendo ocorrer uma interseção entre a competência tributária e a competência material da Pessoa Jurídica de Direito Público para dispor sobre o tema.

\subsubsection{Princípio da legalidade}

O Princípio da Legalidade atua como uma das mais importantes limitações ao poder de estabelecer tributos, previsto no art. 150, I da Constituição Federal. Também o art. 97 do Código Tributário Nacional (CTN) determina que na lei deverá constar todos os elementos necessários para a identificação do fato gerador da obrigação tributária e para a determinação do valor a ser pago pelo tributo.

A legalidade possui um duplo aspecto, formal e material. Para Misabel Abreu Machado Derzi $^{26}$, a legalidade formal determina que apenas a lei, como ato próprio emanado do Poder Legislativo, poderá criar ou majorar o tributo. A legalidade material, por sua vez, estabelece que a lei deverá conceituar os tributos de forma específica, com a previsão dos seus aspectos substanciais.

A Emenda Constitucional $n^{\circ} 03$ de 1993, que alterou o $§ 6^{\circ}$ do art. 150 da CFRB/88, estendeu o princípio da legalidade à concessão de quaisquer subsídios e causas extintivas ou excludentes do crédito tributário, assim, apenas a lei poderá conceder exonerações e outros benefícios redutores, extintivos ou excludentes do crédito tributário. Ademais, os incentivos e benefícios fiscais deverão ser concedidos em caráter temporário, sendo que a lei deverá definir com precisão as condições, a extensões e os limites quantitativos do seu alcance ${ }^{27}$.

Também, Misabel Abreu Machado Derzi ${ }^{28}$ salienta que a legalidade estrita exige que a lei tipifique os fatos jurídicos e seus efeitos e, sempre que possível, limite a imprecisão conceitual, razão pela qual, no Direito Tributário, os conceitos fechados são empregados com maior frequência. Porém, o legislador poderá optar pela formulação de ordens de estrutura flexível, em lugar da utilização de conceitos fechados, a depender do campo jurídico no qual está situado o tema.

Ademais, Luiz Eduardo Schoueri ${ }^{29}$, ao tratar sobre o Princípio da Legalidade Tributária aplicado ao campo do Direito Tributário Ambiental, pontua que, nesta área, o uso de conceitos indeterminados é a regra e não uma exceção. A inserção de cláusulas gerais e de conceitos indeterminados termina por atribuir flexibilidade à norma, tornando-a mais adaptável aos avanços sociais e tecnológicos, o que justifica sua utilização pelo Direito Tributário Ambiental.

Em remate, apenas a lei em sentido estrito poderá conceder, por prazo determinado, incentivos e benefícios fiscais, por força dos art. 150, I e $\$ 6^{\circ}$ da CFRB/88. A lei também deverá prever as condições para a concessão destes incentivos, podendo se utilizar de conceitos indeterminados para tanto, a depender das especificidades de cada área do direito.

\footnotetext{
${ }^{26}$ BALEEIRO, A. Op. cit., p. 73

${ }^{27}$ BALEEIRO, A. Op. cit. p. 101

${ }^{28}$ BALEEIRO, A. Op. cit. p. 137

${ }^{29}$ SCHOUERI, L. E. Op. cit. p. 243
} 


\subsubsection{Princípio da igualdade e princípio da capacidade contributiva}

A Constituição Federal de 1988 situa o Princípio da Igualdade ou Princípio da Isonomia fiscal, em seu art. 150, II, no rol das limitações constitucionais ao poder de tributar. O Princípio da Igualdade Tributária decorre do Princípio mais amplo, da Igualdade de Todos Perante a Lei, art. $5^{\circ}$, caput, da CFRB/88.

Aliomar Baleeiro ${ }^{30}$ ressalta que, em razão do Princípio da Igualdade, não é possível reservar tratamento fiscal diverso aos indivíduos que se encontrem nas mesmas condições, não sendo toleráveis discriminações e isenções que não correspondam a critérios razoáveis e compatíveis com a Constituição. A fonte principal dos critérios discriminatórios é o Princípio da Capacidade Contributiva, o qual recomenda a graduação do imposto segundo a capacidade econômica do contribuinte. Fora dessa regra geral, o autor reconhece que a igualdade ainda cede diante do emprego dos tributos para fins extrafiscais ou de poder de polícia.

Segundo Misabel Abreu Machado Derzi ${ }^{31}$, nas isenções e demais benefícios fiscais, a capacidade contributiva é posta de lado, de forma total ou parcial, uma vez que tais desonerações são direcionadas, geralmente, às pessoas de maior capacidade econômica. Para o autor, os contribuintes favorecidos com tais benefícios são tratados de forma especial, porque apresentam uma maior aptidão para a concretizar os planos governamentais ou mesmo por mérito.

Porém, a medida da igualdade não se esgota no Princípio da Capacidade Contributiva, sendo este apenas um, dentre os diversos fatores de discriminação previstos na Constituição, a exemplo da Essencialidade e dos princípios da Função Social da Propriedade e da Proteção ao Meio Ambiente. No entanto, é importante observar que os critérios de discriminação adotados pela norma não poderão ser arbitrários, motivo pelo qual todo tratamento discriminatório deve ser submetido ao exame da proporcionalidade e da razoabilidade ${ }^{32}$.

No âmbito dos incentivos fiscais ambientais, o sacrifício do Princípio da Capacidade Contributiva deverá passar pelo crivo da proporcionalidade, os tributos ou elementos tributários ambientais deverão ser adequados para alcançar seus objetivos; necessidade ou lesão mínima, se não existem outras medidas igualmente eficazes para a proteção ambiental; proporcionalidade em sentido estrito, ponderação entre os benefícios ambientais e a lesão sofrida pelo Princípio da Capacidade Contributiva ${ }^{33}$.

Portanto, a concessão de incentivos fiscais a algumas classes de contribuintes sofre limitações pelo Princípio da Isonomia Fiscal, o que garante que estes instrumentos estejam de fato direcionados à realização dos interesses constitucionais, evitando a concessão de incentivos fiscais na forma de privilégios aos agentes econômicos.

\subsection{O IPTU verde}

O Princípio da Função Social da Propriedade possui uma dimensão ambiental, com base no art. 170, III e VI, da Constituição, que situa os princípios da Função Social da Propriedade e da Defesa do Meio Ambiente no rol dos princípios da ordem econômica de observância obrigatória para a exploração da propriedade. Este é o entendimento de autores como Luciano Costa

${ }^{30}$ BALEEIRO, A. Op. cit, p. 520

31 BALEEIRO, A. Op. cit., p. 548

${ }^{32}$ SCHOUERI, L. E. Op. Cit., p. $246-248$

33 TABOADA, C. P. El principio "quien contamina paga" y el principio de capacidad económica. In: TÔRRES, H. T. (org). Direito tributário ambiental. São Paulo, SP: Malheiros, 2005. p. 79 - 95. p. 83 - 84 
Miguel e Lucas Azevedo de Lima ${ }^{34}$, os quais também reconhecem que o Direito ao Meio Ambiente Ecologicamente Equilibrado, art. 225 da Carta Magna, consiste em um direito social fundamental inserido no Título VIII da Constituição, que trata sobre a ordem social, motivo pelo qual os ambientalistas se referem ao Princípio da Função Socioambiental da Propriedade.

Ademais, o Estatuto da Cidade, Lei Federal no 10.257/2001, a norma mais importante em assuntos urbanísticos, em seu art. $1^{\circ}$, Parágrafo único, estabelece as diretrizes gerais para o desenvolvimento das cidades, dentre as quais está a regulamentação do uso da propriedade urbana em prol do equilíbrio ambiental. Em seu art. $2^{\circ}$, inciso I, o Estatuto traz a garantia do Direito às Cidades Sustentáveis como uma das diretrizes gerais da política urbana, em complemento, o art. $4^{\circ}$, inciso IV, alínea a) e c), qualifica o Imposto Predial e Territorial Urbano (IPTU) e os incentivos e benefícios fiscais como instrumentos tributários e financeiros a serem utilizados para a concretização da política urbana.

Nesta linha, Regina Helena Costa ${ }^{35}$ reconhece que o IPTU, em seu viés extrafiscal, poderá ser utilizado pelos municípios com o fim de promover o adequado aproveitamento do solo urbano, em atenção à função socioambiental da propriedade, atuando como um importante instrumento na garantia da preservação do meio ambiente.

Tânia Cristina Azevedo ${ }^{36}$ reconhece que os municípios brasileiros, no intuito de estimular o modelo sustentável, criaram leis que possibilitam a redução do IPTU quando o proprietário de imóvel urbano adotar práticas sustentáveis. A autora pontua que tal benefício recebeu denominações como "IPTU VERDE" ou "Ecológico", "IPTU AMBIENTAL" e "IPTU SUSTENTÁVEL", sendo certo que todas essas nomenclaturas dão ênfase à função socioambiental do imposto, que pressupõe o estímulo à adoção de condutas ambientalmente orientadas.

Neste sentido, Gisane Tourinho Dantas ${ }^{37}$ aponta que o IPTU Verde, enquanto sanção premial, oportunizará a concessão de alíquotas reduzidas, descontos e isenções para os contribuintes que executarem alguma ação considerada ambientalmente relevante pela legislação municipal. No Brasil, até o ano de 2016, 16 municípios já contavam com alguma legislação referente ao IPTU Verde ${ }^{38}$, dentre os quais se destacam os municípios de Guarulhos (SP), Curitiba (PR) e Salvador (BA), este último a ser tratado em capítulo próprio.

O Município de Curitiba (PR), por meio da Lei Municipal no 9.806/2000, art. 10º concede isenção ou dedução proporcional da base de cálculo do IPTU para proprietários ou possuidores de terrenos que possuam área verde com bosques nativos, pinheiros isolados ou árvores de grande volume de copada.

A Lei Municipal no 6.793/2010 do Munícipio de Guarulhos (SP), em seu art. 61 determina a concessão de descontos de até $20 \%$ no valor anual a ser pago pelo IPTU pelos imóveis edificados que adotem uma ou mais das medidas elencadas no artigo, dentre as quais está a arborização dos terrenos, a adoção sistemas de captação de água da chuva, reuso da água, utilização de

\footnotetext{
${ }^{34}$ MIGUEL, L. C., LIMA, L. A. de. A função socioambiental do IPTU e do ITR. Cadernos de Direito, São Paulo, SP: Universidade Metodista de Piracicaba, v. 12, n. 23, p. 193 - 2014, jul./dez. 2012. p. 202 - 203

${ }^{35}$ COSTA, R. H. Op. cit., pág. 327

${ }^{36}$ AZEVEDO, T. C. Tributação municipal como incentivo ao desenvolvimento sustentável nas cidades: O caso do IPTU VERDE no município de Salvador. 2017. 299 f. Tese (Doutorado em Planejamento Territorial e Desenvolvimento Social) - Universidade Católica do Salvador, Bahia, 2017. p. 153

${ }^{37}$ DANTAS, G. T. O IPTU Verde como instrumento de efetividade da função socioambiental da propriedade privada urbana. 2014. 116 f. Dissertação (Mestrado em Direito) - Faculdade de Direito, Universidade Federal da Bahia, Bahia, 2014. p. 87

38 AZEVEDO, T. C. Op. cit., p. 159
} 
energias renováveis, dentre outras. $\mathrm{O}$ art. 62 da mencionada lei municipal determina, ainda, isenção do IPTU para áreas de preservação permanente situadas em meio urbano.

\section{O IPTU VERDE E SUA IMPLEMENTAÇÃo NO MUNICÍPIO DE SAL- VADOR-BA}

O Programa de Certificação Sustentável IPTU Verde, adotado pelo município de Salvador-BA, segue uma tendência mundial de incorporação dos conceitos de "Construção Sustentável" e "Edificação Verde" do mercado da construção civil, uma das atividades que causam maior impacto ao meio ambiente.

Patricia Martins Torres de Macedo ${ }^{39}$ faz referência a uma pesquisa realizada pelo Sindicato da Indústria da Construção Civil de São Paulo (SindusCon-SP) em parceria com a Fundação Getúlio Vargas (FGV), que concluiu que o setor da construção civil no Brasil consome cerca de $75 \%$ de tudo que é extraído do meio ambiente. Ademais, dentre todas as atividades produtivas, o setor é o maior gerador de resíduos/entulho. Quanto ao consumo de energia, no Brasil cerca de $44 \%$ de toda a energia elétrica produzida é consumida pelos edifícios, desde a etapa pré-operacional, de construção, até a etapa de ocupação, manutenção e demolição.

Neste contexto, surge o conceito de "Empreendimento Sustentável", empreendimento que incorpora práticas de projeto, construção e operação que reduzam significativamente ou até eliminam, o impacto negativo causado ao meio-ambiente e aos usuários ${ }^{40}$. Os primeiros sistemas de avaliação de desempenho ambiental de edifícios surgiram na Europa, Estados Unidos e Canadá na década de 90 , motivados pelas metas ambientais apresentadas pela ECO-92 e pela “Agenda 21 on Sustainable Construction" 41.

Dentre os sistemas de certificação ambiental internacional, se destacam o sistema britânico Building Research Establishment Environmental Assessment Method (BREEAM), o americano Leadership in Energy and Environmental Design (LEED) e o Hauté Qualité Environmentale (HQE). Sobre o tema, Tânia Cristina Azevedo ${ }^{42}$ observa que no Brasil existem esforços para adequar os sistemas de certificação internacional à realidade do país, a exemplo da versão brasileira do LEED, adaptado pelo Green Building Council Brasil, e do HQE que recebeu a nomenclatura de Alta Qualidade Ambiental (ACQUA HQE). Ainda no âmbito nacional, se destacam os brasileiros Selo Procel Edifica da Eletrobrás e Casa Azul da Caixa Econômica Federal.

Em entrevista realizada com o Secretário da Secretária de Sustentabilidade, Inovação e Resiliência de Salvador - Secis, André Fraga, o secretário reconhece que para a criação do Programa de Certificação Sustentável IPTU Verde de Salvador-BA, o município se baseou nos sistemas de certificação ambiental QUALIVERDE, adotado pelo município do Rio de Janeiro-RJ, e o BH SUSTENTÁVEL, adotado pelo município de Belo Horizonte-MG, selos de sustentabilidade para construção (informação verbal) ${ }^{43}$.

\footnotetext{
${ }^{39}$ MACEDO, P. M. T. de. Avaliação de sustentabilidade em edifícios: Um estudo de indicadores de água e energia na unidade da FIOCRUZ Pernambuco. 2011. 146 f. Dissertação (Mestrado em Engenharia Civil) - Programa de PósGraduação em Engenharia Civil, Universidade Federal de Pernambuco, Recife, 2011. p. 33 -34.

${ }^{40}$ MACEDO, P. M. T. Op. cit. p. 23 - 24

41 AZEVEDO, T. C. Op. cit., p. $85-86$

42 Ibid, p. 89

43 Informação fornecida por André Fraga em entrevista realizada na sede da Secis, em Salvador-BA, em 10 de setembro de 2019.
} 
A autora Tânia Cristina Azevedo ${ }^{44}$ afirma que o modelo do benefício verde adotado pelo Programa Certificação Sustentável IPTU Verde de Salvador -BA foi inspirado na metodologia adotada pelo LEED. Inclusive, a legislação que concede o incentivo admite que as edificações que já possuam as certificações ambientais Procel, LEED, ACQUA HQE e Selo Casa Azul/Caixa, participem do programa.

O benefício verde foi instituído no município de Salvador-BA no ano de 2013, ano em que foram realizadas diversas alterações no Código Tributário e de Rendas do Município de Salvador-BA (CTRMS), especialmente, no âmbito do IPTU, com a atualização do Cadastro Imobiliário do Município para adequá-lo à nova Planta Genérica de Valores (PGV), o que resultou no aumento da arrecadação do imposto nos anos subsequentes. No ensejo deste aumento na arrecadação do tributo, foram instituídos, também, novos incentivos fiscais, a exemplo do IPTU Verde.

A Lei Municipal no ${ }^{\circ} 8.474 / 2013$, em seu art. $5^{\circ}$, prevê a concessão de descontos de até $10 \%$ no valor do imposto aos proprietários de imóveis residenciais e não residenciais que adotem medidas de proteção e recuperação do meio ambiente. No ano seguinte, foi editada a Lei Municipal n ${ }^{\circ} 8.723 / 2014$, alterando o CTRMS, com a previsão de redução de $80 \%$ no valor venal dos terrenos declarados como não edificáveis pela legislação municipal e que não sejam economicamente explorados.

O Decreto Municipal no 25.899/2015 regulamentou os benefícios verdes estipulados nas mencionadas leis, instituindo o Programa de Certificação Sustentável IPTU Verde em edificações, com a concessão de benefícios fiscais aos participantes do programa. Em 2017 foi editado o Decreto Municipal no 29.100/2017, revogando o Decreto Municipal $n^{\circ}$ 25.899/2015, o novo decreto, junto aos seus anexos, constitui o conjunto de normas regulamentadoras do Programa de Certificação Sustentável IPTU Verde no Município.

\subsection{O Decreto Municipal $n^{0}$ 29.100/2007: critérios para a concessão do IPTU Verde}

É possível distinguir dois tipos de benefícios fiscais regulamentados pelo Decreto Municipal no 29.100/2017. O primeiro se refere à redução do valor venal de terrenos declarados como não edificáveis e não explorados situados em áreas de proteção ambiental, enquanto o segundo diz respeito à concessão de descontos no valor total do IPTU para estimular os empreendimentos a adotarem ações de sustentabilidade nas edificações, sendo este o objetivo central do Pro$\operatorname{grama}^{45}$.

Quanto ao primeiro benefício, o art. 11, caput, do Decreto Municipal no 29.100/2017, prevê a redução de $80 \%$ no valor venal dos terrenos declarados como não edificáveis e que não sejam economicamente explorados. Para tanto, serão considerados como terrenos não edificáveis aqueles inseridos em Áreas de Proteção Ambiental - APA e Áreas de Proteção Permanente APP, nos termos da Lei Municipal no 9.069/2016, que estabelece o Plano Diretor de Desenvolvimento Urbano (PDDU).

\footnotetext{
44 AZEVEDO, T. C. Op. cit., p. 93
}

${ }^{45}$ AZEVEDO, T. C. Op. cit., p. 196 
Já o benefício voltado aos empreendimentos sustentáveis, com a concessão de descontos no IPTU, o Decreto Municipal n $n^{\circ} 29.100 / 2017$, em seu art. $1^{\circ}, \S 2^{\circ}$, prevê que poderão se candidatar ao Programa de Certificação Sustentável IPTU Verde os empreendimentos a serem edificados, edificações existentes em processo de ampliação e/ou reforma e, por fim, edificações que já possuam uma das certificações ambientais reconhecidas pela norma. Em relação ao critério subjetivo para a concessão do benefício verde, poderão pleitear o desconto as edificações de uso residencial, comercial, misto, institucional e industrial, art. $1^{\circ}, \S 2^{\circ}$, do mencionado Decreto. Nas edificações constituídas por mais de uma unidade imobiliária, as práticas de sustentabilidade deverão ser relativas à toda edificação e ao lote em que ela está implantada, exceto no caso em que a edificação possua inscrição imobiliária independente das demais, art. $2^{\circ}, \S 1^{\circ}$ e $2^{\circ}$.

O Programa de Certificação Sustentável IPTU Verde estabelece que, aos empreendimentos que adotarem ações de sustentabilidade, será concedida a certificação nas categorias OURO, PRATA ou BRONZE, a depender da pontuação alcançada. No total são 70 ações de sustentabilidade contempladas no ANEXO I do Decreto Municipal no 29.100/2017, a elas são atribuídas pontuações distintas que somadas poderão levar a classificação do empreendimento como postulante à uma das categorias. As ações são divididas em cinco temáticas: a) Gestão Sustentável das Águas; b) Eficiência e Alternativas Energéticas; c) Projetos Sustentáveis; d) Bonificações; e) Emissões de Gases de Efeito Estufa (GEE).

Quanto ao procedimento para postulação do benefício, segundo o Manual IPTU Verde de $2016^{46}$, são três os órgãos competentes para apreciação dos pedidos, a Coelba, a Secretaria de Desenvolvimento Urbano (Sedur) e a Secis. A Sedur e a Secis são os órgãos certificadores, enquanto a Coelba é responsável pela análise das ações na área de Eficiência e Alternativas Energéticas.

Os empreendimentos que desejem participar do Programa de Certificação Sustentável deverão postular a entrada quando da solicitação do Alvará de Construção, Ampliação e/ou Reformas perante a Sedur, obtendo uma Pré-Certificação. A certificação definitiva no Programa apenas ocorre após a finalização das obras e realização de uma vistoria in loco pela Sedur, órgão que vai indicar a pontuação atingida pelo empreendimento e enquadrá-lo na categoria alcançada para emissão do Certificado IPTU Verde. Em seguida, o certificado será anexado ao Alvará de Habite-se a ser enviado à Secretária Municipal da Fazenda (Sefaz Municipal), responsável pela inclusão do imóvel no Cadastro Imobiliário Municipal e pela concessão do desconto no IPTU, segundo o percentual previsto para a categoria atingida.

No que tange aos benefícios fiscais no âmbito do IPTU Verde, o art. $10^{\circ}$ do Decreto $\mathrm{Mu}$ nicipal no 29.100/2017, prevê a concessão de desconto de 5\% para a categoria BRONZE, 7\% para a categoria PRATA, $10 \%$ para a categoria OURO. Importante observar que, para além da concessão dos descontos no IPTU, o Programa também agracia os projetos participantes com a tramitação prioritária nos procedimentos de licenciamento na Sedur, art. $7^{\circ}$, caput e Parágrafo único do Decreto Municipal no 29.100/2017.

O certificado tem validade de três anos e poderá ser renovado após solicitação perante a Secis, o pedido de renovação está submetido à uma reavaliação pela Secretaria e somente farão jus a continuar recebendo o benefício os contribuintes que anualmente estiverem em situação de regularidade fiscal e cadastral, art. $10^{\circ}, \S 1^{\circ}, 2^{\circ}$ e $6^{\circ}$ do mencionado Decreto.

\footnotetext{
${ }^{46}$ MANUAL IPTU VERDE: Manual para aplicação dos requisitos. Salvador: Prefeitura de Salvador, 2015 , p. 15 -17.
} 


\subsection{Os efeitos da implementação do Programa de Certificação Sustentável IPTU Verde no município de Salvador-BA}

Em informação repassada pela Secis em setembro de 2019, até aquele momento existiam cinco empreendimentos que já haviam sido certificados, enquanto treze ainda estavam em processo de avaliação (informação verbal) ${ }^{47}$. Dentre os empreendimentos já certificados, a Caramelo Arquitetos Associados, o Sindicato da Indústria da Construção do Estado da Bahia - Siduscon e a Casa das Árvores foram classificados como categoria OURO, obtendo a pontuação máxima prevista, o Edifício Civil Towers, como categoria PRATA e a Camisas Polo Salvador como EMPREENDIMENTO SUSTENTÁVEL.

Tânia Cristina Azevedo ${ }^{48}$, para elaboração de sua Tese de Doutorado em Planejamento Territorial e Desenvolvimento Social da Universidade Católica de Salvador, realizou visita técnica à sede da Siduscon. Em 2016, o empreendimento pleiteou a participação no Programa de Certificação IPTU Verde do município de Salvador na categoria de edificações existentes que já possuem certificação de práticas sustentáveis, ACQUA HQE. O empreendimento foi contemplado na Categoria OURO e, a partir do exercício fiscal de 2017, obteve o desconto de $10 \%$ no valor a ser pago pelo IPTU ${ }^{49}$.

Segundo os dados coletados pela autora, a nova sede da Siduscon priorizou o reaproveitamento do material de demolição e a redução dos impactos sociais e ambientais nos entornos da obra. Ademais, ao longo da fase de edificação, implementou ações voltadas à eficiência energética e ao reaproveitamento de água de chuva e águas cinzas ${ }^{50}$. O valor total do IPTU da sede da Siduscon-BA, em 2017 foi de R $\$ 67.423,88$, com o desconto referente ao IPTU Verde de R\$ $6.742,38$, o valor líquido pago naquele ano foi de $\mathrm{R} \$ 60.681,50^{51}$.

O Residencial Monvert, lançamento imobiliário residencial no bairro do Horto Florestal de inciativa da OR-Empreendimentos, ainda em fase de construção, também é postulante do benefício IPTU Verde na categoria OURO. O Residencial entrou com o pedido de licença junto a Sedur com o pleito IPTU Verde na mencionada categoria em novembro de 2018 , sendo que a certificação sustentável apenas será concedida ao empreendimento após a finalização das obras, junto ao Alvará de Habite-se.

Em entrevista realizada com a OR-Empreendimentos, uma das engenheiras responsáveis pelo empreendimento avaliou que a implementação de tecnologias verdes ao projeto elevou o custo das obras e que, dentre as práticas de sustentabilidade listadas no Programa de Certificação Sustentável IPTU Verde, algumas já seriam naturalmente adotadas pelo empreendimento residencial. Ademais, a empresa reconhece o investimento em sustentabilidade como algo positivo, pois os descontos no IPTU e as ações sustentáveis se convertem em ferramenta de venda para o cliente (informação verbal) $)^{52}$.

O Secretário da Secis, André Fraga, ao ser indagado sobre os resultados alcançados pelo Programa, ponderou que a publicação do Decreto Municipal no 25.899/2015 se deu em meio à

\footnotetext{
${ }^{47}$ Informação fornecida por André Fraga em entrevista realizada na sede da Secis, em Salvador-BA, em 10 de setembro de 2019.

48 AZEVEDO, T. C. Op. cit., p. 217 - 222

${ }^{49}$ Ibid, p. 220

${ }^{50}$ Ibid, p. $218-219$

${ }^{51}$ Ibid, p. 221

52 Informação fornecida por Rachel Perdigão, engenheira da OR-Empreendimentos, em entrevista realizada de forma virtual, em 10 de Novembro de 2019.
} 
crise no mercado imobiliário, o que ocasionou uma redução drástica no número de empreendimentos lançados na cidade, por isso, o número de beneficiários do Programa, de 2015 para cá, ainda não é tão expressivo, sendo apenas cinco empreendimentos certificados (informação ver(bal) $)^{53}$.

O Secretário pontua que na discussão com o mercado imobiliário foi criada a Outorga Verde, como um meio de estimular a postulação ao Programa do IPTU Verde pelos empreendimentos (informação verbal) ${ }^{54}$. O instituto prevê descontos de até $40 \%$ no valor a ser pago pela outorga onerosa aos empreendimentos que obtiverem, na fase de licenciamento, a Certificação Sustentável IPTU Verde, art. 299 da Lei Municipal nº 9.069/2016.

André Fraga reconhece que, como a maior parte dos empreendimentos imobiliários pleiteiam a concessão da outorga onerosa junto à Prefeitura, os descontos concedidos pela Outorga Verde constituem um fator importante para incentivar os novos empreendimentos a aderirem ao Programa de Certificação Sustentável IPTU Verde (informação verbal) ${ }^{55}$. Atualmente, segundo informação fornecida pela Secis, oito empreendimentos imobiliários já receberam a Outorga Verde que, após finalizadas as obras, se converterão em IPTU Verde (informação verbal) ${ }^{56}$.

Tanto o atual Secretário da Sedur, Sérgio Guanabara, quanto o Secretário da Secis, mencionaram nas entrevistas que o Programa de Certificação Sustentável IPTU Verde, apesar de ainda recente, vem apresentando resultados satisfatórios com o aumento gradativo do número de empreendimentos sustentáveis lançados no município de Salvador, ademais, reconheceram que aos poucos o Programa vem sendo atualizado e modificado de forma a atender melhor seus objetivos (informação verbal) ${ }^{57}$.

Segundo dados fornecidos pela Coelba, desde a implementação do IPTU Verde foram registradas 26 solicitações junto à concessionária para adesão ao Programa, dentre as quais a maioria são empreendimentos novos em processo de licenciamento, sendo poucas as edificações que já possuem outros tipos de certificações sustentáveis e pleiteiam o benefício (informação verbal) ${ }^{58}$.

Tânia Cristina Azevedo ${ }^{59}$ destaca que o Programa de Certificação IPTU Verde implementado no município de Salvador, foi reconhecido pela organização internacional Sustainian, em sua publicação Cities 100 durante a conferência COP21, como uma das 100 soluções apresentadas por 61 cidades do mundo para promoção do desenvolvimento sustentável. A organização reconheceu que o IPTU Verde adotado pela cidade de Salvador está entre as ações que poderão contribuir para a redução das emissões de gás carbônico, através do incentivo ao uso de tecnologias sustentáveis em empreendimentos imobiliários.

${ }^{53}$ Informação fornecida por André Fraga em entrevista realizada na sede da Secis, em Salvador-BA, em 10 de setembro de 2019.

${ }^{54}$ Informação fornecida por André Fraga em entrevista realizada na sede da Secis, em Salvador-BA, em 10 de setembro de 2019.

55 Informação fornecida por André Fraga em entrevista realizada na sede da Secis, em Salvador-BA, em 10 de setembro de 2019.

${ }^{56}$ Informação fornecida por André Fraga em entrevista realizada na sede da Secis, em Salvador-BA, em 10 de setembro de 2019.

${ }^{57}$ Informação fornecida por Sérgio Guanabara em entrevista realizada por meio virtual, em 05 de setembro de 2019 e por André Fraga em entrevista realizada na sede da Secis, em Salvador-BA, em 10 de setembro de 2019.

58 Informação fornecida por funcionário da COELBA em entrevista realizada por meio virtual, em 20 de outubro de 2019.

59 AZEVEDO, T. C. Op. cit., p. 172 
Sobre o tema, Dantas, de Freitas, de Souza, Ferrúa e Schimitt ${ }^{60}$ observam que o emprego de tecnologias sustentáveis na indústria da construção representa um acréscimo ao custo da obra, que não poderá ser suportado inteiramente pela empresa, sob pena de inviabilizar o empreendimento, daí a importância de o Poder Público conceder incentivos na área. Os autores pontuam que o IPTU Verde adotado pela cidade de Salvador está alinhado com esta premissa, posto que os beneficiários recebem incentivos pelos serviços ambientais prestados à municipalidade, reduzindo os impactos que eventuais despesas com a adaptação às práticas sustentáveis poderiam ocasionar aos empreendimentos.

\subsection{Análise crítica}

O art. $5^{\circ}$ da Lei Municipal $n^{\circ} 8.474 / 2013$ e o art. $5^{\circ}$ da Lei Municipal $n^{\circ} 8.723 / 2014$, ao estabelecerem distinções na forma de tributação do IPTU com base em critérios ambientais, estão alinhados com os objetivos constitucionais de promoção da função socioambiental da propriedade urbana e de garantia da preservação do meio ambiente ecologicamente equilibrado, art. 170, III e VI, e art. 225 da CFRB/88. Resta saber se a Lei Municipal e a sua norma regulamentadora atendem às limitações impostas pela Constituição ao legislador local para a concessão de isenções e outros incentivos fiscais no âmbito do imposto.

Primeiro, cumpre discorrer acerca da competência. Por se tratar de um incentivo fiscal ambiental, o ente tributante deverá possuir a competência legislativa para instituir o imposto e a competência material para tratar do fato que se busca excluir do alcance da tributação.

Sobre o tema, Guilherme Paes de Barros Geraldi ${ }^{61}$ dispõe que o município possui competência legislativa tributária em matéria de IPTU, por força dos art. 30, III, e 156, I, da Constituição, segundo os quais compete aos municípios instituir o imposto relativo à propriedade predial e territorial urbana, bem como, promover a sua arrecadação. Quanto ao aspecto material, o autor pontua que a competência para legislar em matéria ambiental é concorrente entre a União, Estados, Distrito Federal e Munícipios, sendo que, neste caso, verifica-se o interesse local, uma vez que a norma se refere aos empreendimentos e terrenos urbanos que causam impactos diretos no munícipio. Portanto, o munícipio é detentor das competências legislativa e material para a instituição de incentivos fiscais ambientais no âmbito do IPTU, não existindo qualquer óbice neste ponto.

Em seguida, passa-se à análise do Princípio da Legalidade. $\mathrm{O}$ art. $150, \S 6^{\circ}$, da Constituição é claro ao determinar que qualquer espécie de desoneração tributária deverá ser estabelecida por lei específica que regule a matéria de forma exclusiva. Ademais, os incentivos previstos na lei deverão ter caráter temporário, não podendo se prolongar indefinidamente no tempo.

A Lei Municipal no 8.474/2013, ao instituir incentivo fiscal ambiental no âmbito do IPTU, prevê a edição de norma específica para regulamentar a forma como ele será concedido. O Decreto Municipal $n^{\circ} 29.100 / 2017$ diz respeito, única e exclusivamente, ao IPTU Verde, seus requisitos e procedimentos, bem como, estabelece o limite temporal de três exercícios financeiros para o gozo do benefício, em consonância, portanto, com o Princípio da Legalidade.

\footnotetext{
${ }^{60}$ DANTAS, M. B., SCHIMMIT, G. B., FREITAS, M. D. G. de., FERRÚA, L., SOUZA, M. D. E. de. Mapeamento de incentivos econômicos para a construção sustentável: A indústria da construção brasileira em busca da sustentabilidade. Florianópolis, SC: CBIC, 2015. p. 71

${ }^{61}$ GERALDI, G. P. de B. Op. cit. p. 250-251
} 
Quanto ao Princípio da Igualdade, Guilherme Paes de Barros Geraldi ${ }^{62}$ explica que, no caso do IPTU Verde, tem-se dois imóveis de idêntico valor venal, o que indica que os proprietários possuem a mesma capacidade contributiva, porém, estão sujeitos a cargas tributárias distintas com a justificativa de garantir a proteção do meio ambiente. De modo que poderá ser questionado até que ponto este critério de discriminação é proporcional e razoável à finalidade ambiental.

Assim, os critérios subjetivos e objetivos previstos pelo Decreto Municipal $\mathrm{n}^{\circ}$ 29.100/2017 para concessão de descontos no âmbito do IPTU passarão a ser analisados à luz da proporcionalidade. Quanto aos sujeitos que poderão ser contemplados pelo benefício, o art. $1^{\circ}$, $\S 2^{\circ}$ do Decreto prevê que são empreendimentos novos ou já existentes de uso residencial, comercial, misto, institucional e industrial, sem restrições quanto ao tipo de edificação, se vertical ou horizontal. Assim, pode-se afirmar que, no âmbito subjetivo, o Decreto optou por abranger todos os empreendimentos, sem discriminações com base no tipo ou na destinação do imóvel, em consonância com o Princípio da Igualdade.

No que tange aos requisitos objetivos para obtenção da Certificação IPTU Verde, Tânia Cristina Azevedo ${ }^{63}$ reconhece que o modelo adotado pelo município de Salvador foi inspirado na certificação internacional de edificações sustentáveis LEED, motivo pelo qual o sistema de pontuação termina por priorizar a postulação de empreendimentos imobiliários específicos, que possuem mais possibilidades, inclusive econômicas, para obter uma certificação deste tipo.

Ademais, a autora observa que, dentre as ações contempladas, poucas visam a melhoria da qualidade urbana nos entornos da edificação, a maior parte das práticas de sustentabilidade contempladas pelo Programa beneficiam de forma direta apenas os empreendimentos. Assim, em paralelo com a "Tripple Bottom Line" e os Objetivos de Desenvolvimento Sustentável para as cidades definidos pela ONU (ODS), dentre às ações reconhecidas no ANEXO I, do Decreto Municipal, apenas 8 são voltadas a geração de impactos positivos no ambiente urbano externo ${ }^{64}$.

Segundo o ANEXO I do Decreto Municipal no 29.1000/2017, dentre as ações de sustentabilidade previstas, 28 ações estão na categoria Eficiência Energética e juntas somam 165 pontos, de modo que o empreendimento que adotar apenas ações deste tipo poderia pleitear o desconto máximo no IPTU na categoria OURO. Em oposição, Tânia Cristina Azevedo ${ }^{65}$ afirma que, caso o empreendimento opte por adotar apenas ações voltadas à melhoria da qualidade urbana nos entornos da edificação, ainda assim não seria suficiente para obter a Certificação Sustentável, devido à baixa pontuação atribuída a este conjunto de ações. Esta discriminação feita pela norma, quanto à distribuição distinta de pontos entre as categorias de ações, não está integrada com os objetivos traçados pela ONU na Agenda 2030, mais especificamente, o Objetivo de Desenvolvimento Sustentável (ODS) $n^{\circ} 11$, Cidades e Comunidades Sustentáveis, que abrange tanto as tecnologias verdes, quanto as medidas voltadas à promoção de impactos sociais positivos nas cidades.

Por isso, os critérios discriminatórios de caráter objetivo adotados pela norma e seu sistema de pontuação, não passam pelo crivo da proporcionalidade nem da razoabilidade. Existem ações igualmente eficazes para promover a sustentabilidade nos empreendimentos e que se mostram mais acessíveis aos contribuintes, mas que não foram contempladas pela norma ou a elas lhes foi atribuída pontuação inferior, a exemplo das ações voltadas a promoção de impacto social positivo nos entornos das edificações.

\footnotetext{
${ }^{62}$ Ibid, loc. cit.

${ }^{63}$ AZEVEDO, T. C. Op. cit. p. 197 - 206

${ }^{64}$ AZEVEDO, T. C. Op. cit. p. 204

${ }^{65}$ AZEVEDO, T. C. Op. cit. p. 205
} 
Quanto ao procedimento adotado, segundo Tânia Cristina Azevedo ${ }^{66}$, o que se observa hoje é que o acesso ao programa se torna restrito aos empreendimentos de classe alta e à alguns tipos de edificações comerciais e institucionais em razão do grande número de exigências e da burocracia dos procedimentos.

Portanto, as ações de sustentabilidade e a distribuição de pontos, conforme disposto no Programa de Certificação Sustentável IPTU Verde, bem como, o procedimento para concessão do benefício, limitam o acesso ao Programa aos empreendimentos imobiliários de grande porte, em oposição ao Princípio da Igualdade.

\section{CONSIDERAÇÕES FINAIS}

Por fim, o presente trabalho chegou às seguintes conclusões:

a) Os tributos, em sua dimensão extrafiscal, são utilizados pelo Estado para a concretização de valores constitucionais, dentre os quais se destaca a Defesa do Meio Ambiente Ecologicamente Equilibrado.

b) A política de conceder incentivos fiscais na área ambiental, se comparada ao modelo repressivo tradicionalmente adotado pelo Estado, é mais eficaz para a formação de uma consciência ambiental no contribuinte, isto se deve ao seu caráter não coativo, atuação preventiva (antes da ocorrência do dano) e à sua menor onerosidade.

c) A concessão de incentivos fiscais deve estar condicionada aos limites constitucionais ao poder de tributar, sob pena de o instituto converter-se em um verdadeiro favor fiscal prestado a alguns poucos agentes econômicos, sem uma contrapartida ambiental relevante.

d) A proteção do meio ambiente é um critério discriminatório reconhecido pela Constituição para justificar a concessão de tratamentos tributários distintos para contribuintes que possuam a mesma capacidade econômica, sem que isso represente uma violação aos Princípios da Igualdade e da Capacidade Contributiva, desde que sejam adequados, necessários e proporcionais à realização de tal fim.

e) O incentivo fiscal ambiental IPTU Verde é uma importante ferramenta à disposição dos municípios para estimular os proprietários de imóveis urbanos a adotarem condutas sustentáveis em prol da manutenção do equilíbrio ambiental, e, gradativamente, vem contribuindo para a consolidação de um mercado imobiliário "verde" nas cidades.

f) O Programa de Certificação Sustentável IPTU Verde de Salvador-BA ainda não se consagrou como um instrumento eficaz para promoção da sustentabilidade urbana. Desde 2015, ano em que foi implementado, o Programa apenas concedeu a certificação sustentável à 8 edificações, em sua maioria empreendimentos comerciais.

g) Os critérios objetivos e a forma de distribuição das pontuações adotados pelo Programa provaram ser um óbice à participação de empreendimentos residenciais de pequeno e médio porte. Ao atribuir pontuações mais altas às ações que demandam um investimento maior para sua implementação, o Programa eleva os custos financeiros para a adoção das práticas sustentáveis, reduzindo seu alcance aos empreendimentos comerciais e residenciais de grande porte. Assim, o modelo de incentivo fiscal atualmente adotado, neste as-

${ }^{66}$ AZEVEDO, T. C. Op. cit. p. $230-231$ 
pecto, é considerado inconstitucional por violação do Princípio da Igualdade e prevê critérios arbitrários que restringem o acesso ao benefício à um segmento imobiliário específico.

h) A burocracia que envolve o procedimento repele possíveis postulações ao benefício. Atualmente, o procedimento é realizado em duas fases que tramitam perante três órgãos municipais. A fase de Pré-Certificação poderia ser simplificada uma vez que é apenas a certificação definitiva que gera o desconto no valor do IPTU. Ademais, a análise das postulações poderia envolver menos órgãos municipais.

\section{REFERÊNCIAS}

ALMEIDA, F. C. R. de. Uma abordagem estruturada da renúncia de receita pública federal. Revista do Tribunal de Contas da União, Brasília, v. 31, n. 84, p., abr./jun. 2000. Disponível em: https://revista.tcu.gov.br > ojs > index.php > RTCU > article > view. Acesso em: 20 de out. 2019.

ALTAMIRANO, A. C. El derecho tributario ante la constitucionalización del derecho a un medio ambiente sano. In: TÔRRES, H. T. (org). Direito tributário ambiental. São Paulo, SP: Malheiros, 2005. p. 445 - 526.

AMARAL, P. H. do. Tributação Ambiental: contributo à política de desenvolvimento sustentável no Brasil. Revista de Direito Ambiental, São Paulo, SP: Revista dos Tribunais, ano 13, n. 50, p. 212 - 234, abr.jun. 2008.

ATALIBA, G. Hipótese de incidência tributária. 5. ed. São Paulo, SP: Malheiros, 1999.

ATALIBA, G., GONÇALVES, J. A. L. Crédito-prêmio de IPI - Direito adquirido - Recebimento em dinheiro. Revista de Direito Tributário. São Paulo, SP: Revista dos Tribunais, v. 15, n. 55, p. 162 - 179, jan./mar.1991.

AZEVEDO, T. C. Tributação municipal como incentivo ao desenvolvimento sustentável nas cidades: O caso do IPTU VERDE no município de Salvador. 2017. 299 f. Tese (Doutorado em Planejamento Territorial e Desenvolvimento Social) - Superintendência de Pesquisa e Pós-Graduação, Universidade Católica do Salvador, Salvador, 2017.

BALEEIRO, A. Limitações constitucionais ao poder de tributar. 7. ed. rev. e compl. por Misabel Abreu Machado Derzi. Rio de Janeiro, RJ: Forense. 1997.

BALEEIRO, A. Uma introdução à ciência das finanças. 15. ed. rev e atual. Rio de Janeiro, RJ: Forense, 1997.

BORGES, J. S. M. Isenções tributárias. 2. ed. São Paulo, SP: Sugestões literárias S/A, 1980.

BRANDÃO, R. F. Incentivo fiscal ambiental: Parâmetros e limites para sua instituição à luz da Constituição Federal de 1988. 2013. 267 f. Tese (Doutorado em Direito) - Faculdade de Direito, Universidade de São Paulo, São Paulo, 2013.

BRASIL. Constituição (1988). Constituição da República Federativa do Brasil. Brasília, DF: Senado, 1988.

BRASIL. Lei $\mathrm{n}^{\circ}$ 6.938, de 31 de agosto de 1981. Dispõe sobre a Política Nacional do Meio Ambiente, seus fins e mecanismos de formulação e aplicação, e dá outras providências. Brasília. Diário Oficial. Ano 1981. Disponível em: http://www.planalto.gov.br/ccivil 03/Leis/L6938. htm. Acesso em: 02 out. 2019. 
BRASIL. Lei n ${ }^{\circ} 5.172$ de 25 de outubro de 1966. Dispõe sobre o Sistema Tributário Nacional e institui normas gerais de direito tributário aplicáveis à União, Estados e Municípios. Brasília. Diário Oficial. Ano 1966. Disponível em: http://www.planalto.gov.br/ccivil_03/leis/15172.htm. Acesso em: 05 out. 2019.

BRASIL. Lei ${ }^{\circ} 5.106$ de 2 de setembro de 1966. Dispõe sobre os incentivos fiscais concedidos a empreendimentos florestais. Brasília. Diário Oficial da União. Disponível em: https://www2. camara.leg.br/legin/fed/lei/1960-1969/lei-5106-2-setembro-1966-368482-norma-pl.html.

Acesso em: 20 out. 2019.

BRASIL. Lei no 9.393, de 19 de dezembro de 1996. Dispõe sobre o Imposto sobre a Propriedade Territorial Rural - ITR, sobre pagamento da dívida representada por Títulos da Dívida Agrária e dá outras providências. Brasília. Diário Oficial da União. Disponível em: http://www.planalto. gov.br/ccivil_03/leis/L9393.htm. Acesso em: 20 out. 2019.

BRASIL. Lei no 10.257, de 10 de julho de 2001. Regulamenta os arts. 182 e 183 da Constituição Federal, estabelece diretrizes gerais da política urbana e dá outras providências. Brasília. Diário Oficial da União. Disponível em: http://www.planalto.gov.br/ccivil_03/LEIS/LEIS 2001/ L10257.htm. Acesso em: 01 nov. 2019.

BRASIL. Lei Complementar $n^{\circ} 101$ de 4 de maio de 2000. Estabelece normas de finanças públicas voltadas para a responsabilidade na gestão fiscal e dá outras providências. Brasília. Diário Oficial da União. Ano 2000. Disponível em: http://www.planalto.gov.br/ccivil_03/leis/lcp/ lcp101.html Acesso em: 4 dez. 2019.

COSTA, R. H. Apontamentos sobre a tributação ambiental no Brasil. In: TÔRRES, H. T. (org). Direito tributário ambiental. São Paulo, SP: Malheiros, 2005. p. 312-332.

CURITIBA. Lei no 9.806 de 3 de janeiro de 2000. Institui o Código Florestal do Município de Curitiba e dá outras providências. Curitiba. Diário Oficial do Município. Disponível em: https:/ /www.curitiba.pr.gov.br/conteudo/legislacao-smma/347. Acesso em 5 ago. 2019.

DANTAS, G. T. O IPTU Verde como instrumento de efetividade da função socioambiental da propriedade privada urbana. 2014. 144 f. Dissertação (Mestrado em Direito) - Faculdade de Direito, Universidade Federal da Bahia, Bahia, 2014.

DANTAS, M. B., SCHIMMIT, G. B., FREITAS, M. D. G. de., FERRÚA, L., SOUZA, M. D. E. de. Mapeamento de incentivos econômicos para a construção sustentável: A indústria da construção brasileira em busca da sustentabilidade. Florianópolis, SC: CBIC, 2015.

GERALDI, G. P. de. B. O IPTU Verde em São Paulo: Análise crítica do projeto de lei municipal $n^{\circ}$ 568/2015. Revista Forense, Rio de Janeiro, RJ: Forense, v. 424, p. 235-254, jul./dez. 2016.

GUARULHOS. Lei nº 6.793 de 28 de dezembro de 2010. Dispõe sobre o lançamento, arrecadação e fiscalização do imposto sobre a propriedade predial e territorial urbana - IPTU e dá outras providências. Diário Oficial do Município. Disponível em: https://leismunicipais.com.br/a/sp/ g/guarulhos/lei-ordinaria/2010/680/6793. Acesso em: 05 ago. 2019.

GUIMARÃES, L. C. Direito ambiental e extrafiscalidade dos impostos no direito tributário brasileiro. Revista dos Mestrandos em Direito Econômico da UFBA, Salvador: Centro Editorial e Didático da UFBA, n. 5, p. 345-357, jan. 1996/dez. 1997.

MACEDO, P. M. T. de. Avaliação de sustentabilidade em edifícios: Um estudo de indicadores de água e energia na unidade da FIOCRUZ Pernambuco. 2011. 146 f. Dissertação (Mestrado em Engenharia Civil) - Programa de Pós-Graduação em Engenharia Civil, Universidade Federal de Pernambuco, Recife, 2011. 
MACHADO, H. de B. Curso de direito tributário. 38. ed. ver. e atual. São Paulo, SP: Malheiros, 2017.

MANUAL IPTU VERDE: Manual para aplicação dos requisitos. Salvador: Prefeitura de Salvador, 2015.

MIGUEL, L. C., LIMA, L. A. de. A função socioambiental do IPTU e do ITR. Cadernos de Direito, São Paulo, SP: Universidade Metodista de Piracicaba, v. 12, n. 23, p. 193-2014, jul./dez. 2012.

MOLINA, P. M. H., VASCO, D. C. Marco conceptual, constitucional y comunitario de la fiscalidad ecológica. In: TÔRRES, H. T. (org). Direito tributário ambiental. São Paulo, SP: Malheiros, 2005. p. $96-156$.

ORGANIZAÇÃO DAS NAÇÕES UNIDAS. Transformando Nosso Mundo: A Agenda 2030 para o Desenvolvimento Sustentável. 2015. Disponível em: https://nacoesunidas.org/wp-content/uploads/2015/10/agenda2030-pt-br.pdf. Acesso em: 06 de nov. 2019.

ORGANIZAÇÃO DAS NAÇÕES UNIDAS. Declaração do Rio sobre o meio ambiente e desenvolvimento. Rio de Janeiro, RJ, 1992. Disponível em: http://www.meioambiente.pr.gov.br/ arquivos/File/agenda21/Declaracao_Rio_Meio_Ambiente_Desenvolvimento.pdf. Acesso em: 15 de out. 2019.

PINTO, K. A. V. S. Introdução ao direito ambiental tributário. Campinas, SP: Editora Alínea, 2012.

SALVADOR. Lei $\mathrm{n}^{\circ} 8.474$ de 02 de outubro de 2013. Altera dispositivos da Lei $\mathrm{n}^{\circ} 7.186$, de 27 de dezembro de 2006, relativos ao pagamento, à isenção do imposto sobre a propriedade predial e territorial urbana - IPTU, concede incentivos fiscais, e dá outras providências. Salvador. Diário Oficial do Município. Disponível em: https://www.legisweb.com.br/legislacao/?id=260282. Acesso em: 10 nov. 2019.

SALVADOR. Lei $\mathrm{n}^{\circ} 8.723$ de 22 de dezembro de 2014. Altera, acrescenta e revoga dispositivos da Lei $n^{\circ} 7.186$, de 27 de dezembro de 2006, relativos à redução de alíquota e de valor do pagamento do Imposto sobre a Propriedade Predial e Territorial Urbana - IPTU, concede remissão e incentivos fiscais e dá outras providências. Salvador. Diário Oficial do Município. Disponível em: https://www.legisweb.com.br/legislacao/?id=279291. Acesso: 10 nov. 2019.

SALVADOR. Decreto Lei $n^{\circ} 29.100$ de 07 de março de 2017. Regulamenta o art. $5^{\circ}$ da Lei $n^{\circ}$ 8.474, de 02 de outubro de 2013, e institui o Programa de Certificação Sustentável "IPTU VERDE" em edificações no Município de Salvador, que estabelece benefícios fiscais aos participantes do programa, assim como o art. $5^{\circ}$ da Lei 8.723 de 22 de dezembro de 2014 e dá outras providências. Salvador. Diário Oficial do Município. Disponível em: iptuverde.salvador.ba.gov.br > downloads > Decreto. Acesso em: 20 out. 2019.

SALVADOR. Lei n ${ }^{\circ} 9.069$ de 30 de junho de 2016. Dispõe sobre o Plano Diretor de Desenvolvimento Urbano do Município de Salvador - PDDU 2016 e dá outras providências. Salvador. Diário Oficial do Município. Disponível em: www.sucom.ba.gov.br > 2016/07 > LEI-n.-9.069PDDU-2016.pdf. Acesso em: 01 nov. 2019.

SANTANA, H. J. de. Justiça fiscal e extrafiscal nos tributos ambientais. Revista do Programa de Pós-Graduação em Direito da UFBA/ Faculdade de Direito, Salvador: EDUFBA, n. 11, p. 37-56, jan./dez. 2004.

SHOUERI, L. E. Normas tributárias indutoras em matéria ambiental. In: TÔRRES, H. T. (org). Direito tributário ambiental. São Paulo, SP: Malheiros, 2005. p. 235-256. 
TABOADA, C. P. El principio "quien contamina paga" y el principio de capacidad económica. In: TÔRRES, H. T. (org). Direito tributário ambiental. São Paulo, SP: Malheiros, 2005. p. 7995.

TÔRRES, H. T. Da relação entre competências constitucionais tributária e ambiental - os limites dos chamados "tributos ambientais". In: TÔRRES, H. T. (org). Direito tributário ambiental. São Paulo, SP: Malheiros, 2005. p. 96-156.

TUPIASSU, L. V. da C. Tributação ambiental: a utilização de instrumentos econômicos e fiscais na implementação do direito ao meio ambiente saudável. Rio de Janeiro, RJ: Renovar, 2006.

VASQUES, D. F., SANTOS, L. C. F., SELLMAN, M. Z. Direito ambiental tributário como garantia da sustentabilidade no Brasil. Revista Magister de Direito Ambiental e Urbanístico, Porto Alegre: Lex Magister, v. 76, p. 29-52, fev./mar. 2018.

YOSHIDA, C. Y. M. Ênfase na prevenção. A utilização econômica dos bens ambientais e suas implicações. In: TORRES, H. T. (org). Direito tributário ambiental. São Paulo, SP: Malheiros, 2005. p. 527-564.

Submetido em: 12 jan. 2020.

Aceito em: 23 jun. 2021. 